\title{
Optimum Copper to Superconductor Ratio in Cables for Superconducting Magnets at $1.9 \mathrm{~K}$
}

CERN AT/93-44 (MA)

LHC Note 254

R. Wolf

\begin{abstract}
In this paper the optimum copper to superconducting ratio is calculated to prevent quenching for superconducting cables used in accelerator magnets like the LHC dipoles, operating in superfluid helium at $1.9 \mathrm{~K}$.

The duration of the perturbations leading to a quench are estimated from flux measurements made with pickup coils in the LHC dipole models.

The optimum copper to superconducting ratio is then found by studying the minimum quench energy and the influence of the length and the duration of the perturbation and heat transfer to the surroundings. A comparison is made of the behaviour at temperatures of 1.9 and $4.3 \mathrm{~K}$.
\end{abstract}





\title{
Optimum Copper to Superconductor Ratio in Cables for Superconducting Magnets at $1.9 \mathrm{~K}$
}

\author{
R. Wolf \\ CERN, European Organization for Nuclear Research, \\ CH-1211 Geneva 23, Switzerland
}

\begin{abstract}
In this paper the optimum copper to superconducting ratio is calculated to prevent quenching for superconducting cables used in accelerator magnets like the LHC dipoles, operating in superfluid helium at $1.9 \mathrm{~K}$.

The duration of the perturbations leading to a quench are estimated from flux measurements made with pickup coils in the LHC dipole models.

The optimum copper to superconducting ratio is then found by studying the minimum quench energy and the influence of the length and the duration of the perturbation and heat transfer to the surroundings. A comparison is made of the behaviour at temperatures of 1.9 and $4.3 \mathrm{~K}$.
\end{abstract}

\section{INTRODUCTION}

This study was made in the framework of the development of superconducting dipole models at CERN for the large hadron collider (LHC) project [1]. A change of cable design was considered with a smaller copper to superconductor ratio for the strands. This study is similar to other studies made on this subject [3]-[10], but it specifically considers the fact that the superconducting dipoles work in superfluid helium at a temperature of $1.9 \mathrm{~K}$, and takes into account quench measurements on the models itself to establish the time scale and magnitude of the perturbations.

At the moment, the strands in the LHC cables have a copper to superconductor ratio between 1.6:1 and 1.8:1. A number of reasons may exist for not going to a lower ratio like protection during quench or mechanical properties of the cable. This paper tries to find if a lower (say 1.3:1) copper to superconductor ratio could be accepted, by looking at the maximum possible thermal perturbation causing a quench, as function of the $\mathrm{Cu}: \mathrm{Sc}$ ratio. These calculations were made on a strand by solving the heat balance equation with the following assumptions:

- The Cu:Sc ratio is varied, but the cross-section of the strand is kept constant. This effectively means that the magnet cross-section stays the same and that the load line does not change.

- The transport current is supposed to remain constant, which means that current transfer to neighbouring strands is supposed to be negligible at the onset of the quench.

- The heat balance equation is taken as 1-dimensional at the start of the quench and thermal contact to the surroundings is taken into account by a heat transfer term.

\section{EXPERIMENTS ON LHC DIPOLE MODELS.}

\section{A. Measurement of Perturbations which Lead to a Quench}

Voltage measurements on the magnet coils and flux measurements on pickup coils in the dipole aperture [2] during training of the LHC dipole models have lead to the following conclusions:

- Quenches are often preceded by events of a duration not longer than typically 200 to $300 \mu s$, which are interpreted as mechanical movements somewhere in the structure.

- The energy contained in these events calculated from the measured voltages and simple models of mechanical movement is often sufficient to quench a considerable part of the winding.

- The quench does not necessarily start where the event took place. The mechanical perturbation can travel with the speed of sound through the structure and induce the quench somewhere else.

\section{$B$. Heat Exchange with the Surroundings}

Any stability calculation must take into account the heat transfer from the strands in the cable to the superfluid helium. The superconducting cable is insulated with a polyimide tape and a second layer of glass fiber tape, impregnated with epoxy resin. Heat transfer measurements performed at CEA-Saclay [11], have shown that for steady state heat transfer the effective heat transfer is determined by the polyimide layer $\left(\mathrm{h} \sim 50 \mathrm{~W} / \mathrm{m}^{2}\right)$. For pulsed heat transfer, however, the polyimide layer may have to be considered as a 'sponge' penetrated by superfluid helium. Therefore the stability calculations are performed for heat transfer values ranging from $50 \mathrm{~W} / \mathrm{m}^{2}$ to $5000 \mathrm{~W} / \mathrm{m}^{2}$.

\section{Calculation of an OPTimum Copper to SUPERCONDUCTING RATIO}

\section{A. Method}

The method involves solving the one dimensional heat balance equation.

$\frac{d}{d x} k \frac{d T(x, t)}{d x} O c u+\frac{\rho_{\alpha x} . I t}{O c u} I c u-h P(T(x, t)-T 0)+\dot{Q}(x, t)=C \frac{d T(x, t)}{d t} O$ 
TABLE I

LIST OF PARAMETERS

\begin{tabular}{|c|c|c|}
\hline Parameter & Description & Unit(SI) \\
\hline B & magnetic field & $\mathrm{T}$ \\
\hline $\mathrm{Bq}$ & quench field on the load line & \\
\hline $\mathrm{C}^{2}$ & $\begin{array}{l}\text { heat capacity of strand per unit } \\
\text { volume }\end{array}$ & $\mathrm{J} / \mathrm{m}^{3}$ \\
\hline $\mathrm{C}_{\mathrm{Cu}}$ & $\begin{array}{l}\text { heat capacity of copper per unit } \\
\text { volume }\end{array}$ & $\mathrm{J} / \mathrm{m}^{3}$ \\
\hline $\mathrm{C}_{\mathrm{NbTi}}$ & $\begin{array}{l}\text { heat capacity of } \mathrm{NbTi} \text { per unit } \\
\text { volume }\end{array}$ & $\mathrm{J} / \mathrm{m}^{3}$ \\
\hline $\mathrm{Cu}: \mathrm{Sc}$ & $\begin{array}{l}\text { copper to superconductor ratio } \\
\text { in the strands }\end{array}$ & \\
\hline f & $\begin{array}{l}=\mathrm{I} t / \mathrm{Iq} \text {, the transport current } \\
\text { relative to the quench current } \\
\text { on the load line }\end{array}$ & \\
\hline h & linear heat transfer coefficient & $\mathrm{W} / \mathrm{m}^{2} / \mathrm{K}$ \\
\hline Ico & $\begin{array}{l}\text { critical current at operating } \\
\text { condition }\end{array}$ & A \\
\hline Icu & current in copper matrix & A \\
\hline $\mathrm{Jc}$ & current density in $\mathrm{NbTi}$ & $\mathrm{A} / \mathrm{m}^{2}$ \\
\hline It & transport current & A \\
\hline Iq & quench current & $\mathbf{A}$ \\
\hline $\mathbf{k}$ & heat conductivity of copper & $\mathrm{W} / \mathrm{m} / \mathrm{K}$ \\
\hline $\mathrm{O}$ & cross section of the strand & $\mathrm{m}^{2}$ \\
\hline $\mathrm{Ocu}$ & copper cross-section & $\mathrm{m}^{2}$ \\
\hline Osc & $\begin{array}{l}\text { superconductor (i.e. NbTi) } \\
\text { cross-section }\end{array}$ & $\mathrm{m}^{2}$ \\
\hline $\mathbf{P}$ & strand perimeter & m \\
\hline Q & $\begin{array}{l}\text { heat pulse power per unit } \\
\text { length }\end{array}$ & $\mathrm{W} / \mathrm{m}$ \\
\hline Qp & energy of heat pulse & $\mathbf{J}$ \\
\hline rrr & $\begin{array}{l}\text { ratio of copper resistivity at } \\
300 \mathrm{~K} \text { and } 4.2 \mathrm{~K}\end{array}$ & \\
\hline $\mathbf{T}$ & local temperature & $\mathbf{K}$ \\
\hline Tc & critical temperature & $\mathbf{K}$ \\
\hline Ts & current sharing temperature & $\mathrm{K}$ \\
\hline $\mathrm{t}$ & time & $\mathbf{s}$ \\
\hline $\operatorname{tmax}$ & duration of heat pulse & $\mathbf{s}$ \\
\hline $\mathbf{x}$ & $\begin{array}{l}\text { position, the heat pulse is } \\
\text { always centered on } x=0 \text {. }\end{array}$ & $\mathrm{m}$ \\
\hline $\mathbf{x} 0$ & $\begin{array}{l}\text { half length of gaussian heat } \\
\text { pulse }\end{array}$ & m \\
\hline$\rho_{\mathrm{cu}}$ & copper resistivity & $\Omega \mathrm{m}$ \\
\hline
\end{tabular}

A Kapitza type heat transfer, proportional to $\mathrm{T}^{\mathrm{n}}-\mathrm{T} 0^{\mathrm{n}}$ with $\mathrm{n} \sim 3$ can also be taken into account. See table 1 for the meaning of the parameter names. The current in the copper matrix, Icu, depends on the temperature as Icu=It-Ic0*(T-TO)/(Tc-T0) when $\mathrm{Ts}<\mathrm{T}<\mathrm{Tc}$ while $\mathrm{Icu}=0$ when $T<T s$ and Icu=It when $T>T c$. The current sharing temperature $\mathrm{Ts}$ is defined as $\mathrm{Ts}=\mathrm{T} 0+\mathrm{I} t / \mathrm{Ic} 0 *(\mathrm{Tc}-\mathrm{T} 0)$. The heat pulse power $Q(x, t)$ is assumed to be of a gaussian form:
$\mathrm{Cu} / \mathrm{Sc}=1.80, \mathrm{RRR}=100 ., \mathrm{H}=0.0 \mathrm{~W} / \mathrm{cm} * 2 / \mathrm{K}$

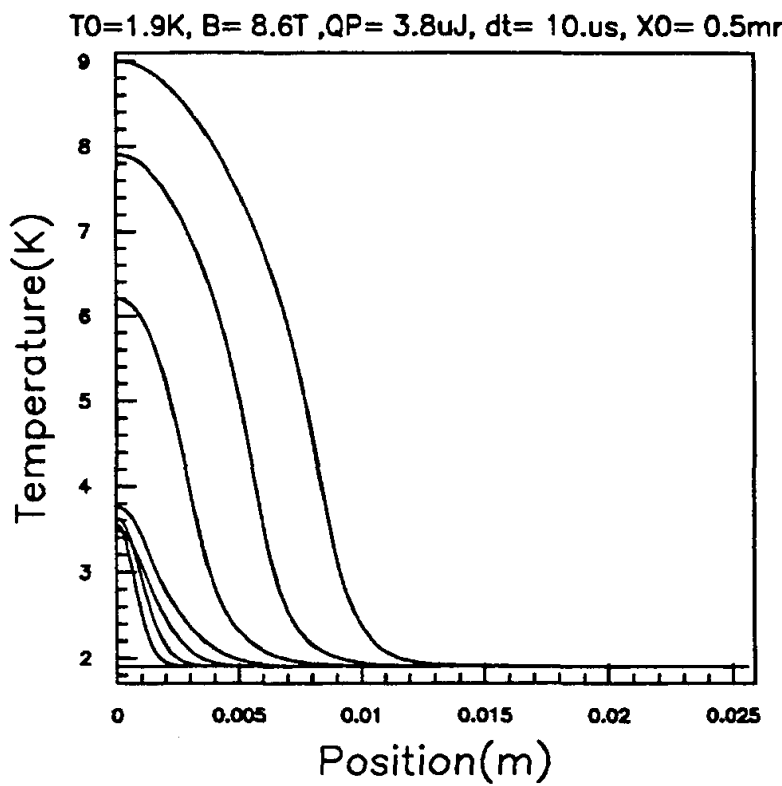

Fig. 1. An example of temperature profiles after a heat pulse of duration $10 \mu \mathrm{s}$ and energy $3.8 \mu \mathrm{J}$ over $1 \mathrm{~mm}$ which just initiates a quench, with no heat exchange to the surroundings.

$\dot{Q}(x, t)=\frac{Q p e^{-\left(\frac{x}{x 0}\right)^{2}}}{2 \sqrt{\pi} x 0 t \max }$

where $2 * x 0$ is considered the length of the perturbation.

This equation is solved numerically and the energy is determined which just causes a quench. An example of such a calculation giving the temperature rise and electric field over the strand is shown in Fig. 1 and 2.

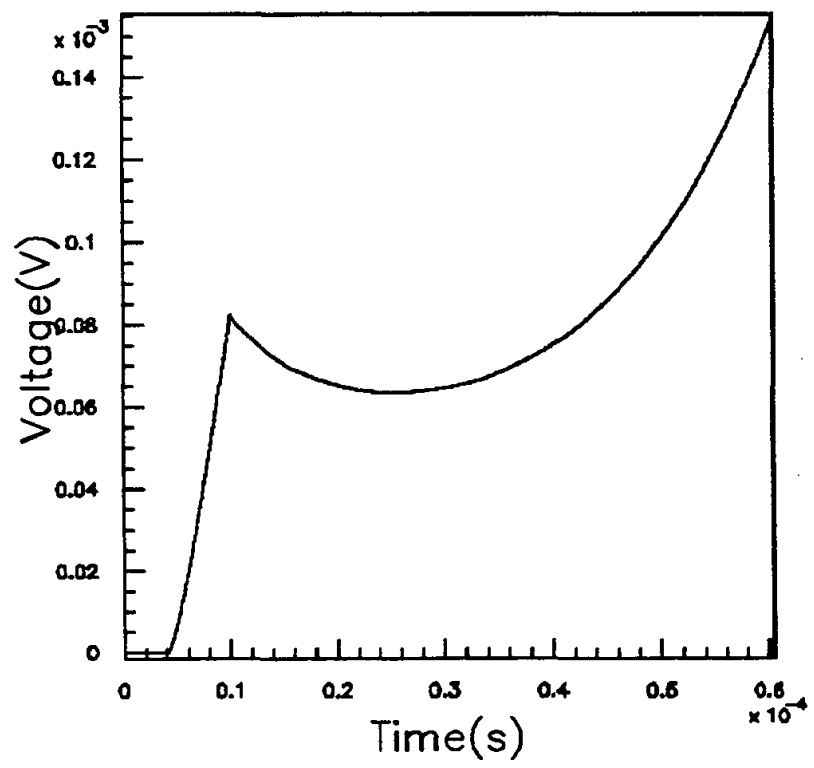

Fig. 2. The electric field integral over the strand for the example in Fig. 1. 


\section{B. Typical Strand Operating Conditions}

The calculations are performed at $T=1.9 \mathrm{~K}$ and $\mathrm{T}=4.3 \mathrm{~K}$ at various field levels. The magnet operating conditions are imitated by considering a strand with a diameter of $0.835 \mathrm{~mm}$ and a Cu:Sc ratio of 1.8 , operating with the same current-field relationship as the central dipole field. Some parameters at the usual operating condition at $90 \%$ of critical current $(\mathrm{f}=0.9)$ are listed below.

\begin{tabular}{lll}
\hline Parameter & Value at $\mathrm{T}=1.9 \mathrm{~K}$ & Value at $4.3 \mathrm{~K}$ \\
\hline & & \\
B & 8.59 & 6.60 \\
It & 314 & 241 \\
Tc & 5.42 & 6.43 \\
Cu:Sc & 1.8 & 1.8 \\
Irr & 100 & 100 \\
Iq & 349 & 268 \\
Bq & 9.55 & 7.33 \\
Ts & 3.06 & 4.93 \\
C & 631 & 2650 \\
\hline
\end{tabular}

\section{RESULTS FOR PERTURBATIONS OF LONG LENGTH}

There is a fundamental difference between a perturbation spread out over a short or a long length. In the first case the heat conduction along the length of the strand plays an important role due to the large temperature gradient and the short length of the normal region, leading to a higher quench energy. In practice for a long perturbation the current density is so high that the heat conduction at the ends plays no role. From Fig. 3 we see that 'long' means longer than a few millimeters only.

For heat pulses with a duration of up to $200 \mu$ s the quenching depends mainly on the heat capacity of the strand and thus favours a low copper to superconducting ratio. The calculations show that only at very high heat transfer rates, of the order of $20000 \mathrm{~W} / \mathrm{m}^{2}$, not feasible in the LHC magnet, would a copper to superconductor ratio larger than 1.8 be advisable.

\section{RESULTS FOR PERTURBATIONS OF SHORT LENGTH}

Perturbation of short length would seem the most probable. Local stress release, i.e. due to resin cracking, belongs to this category and even friction due to movement on a larger scale would deposit energy on perhaps many smaller regions. Therefore, the calculations have been usually made for a pulse length of $1 \mathrm{~mm}$, close to strand diameter.

An optimum copper to superconductor ratio could appear because if there is more copper, more heat can be conducted away, however at the same time the quench temperature becomes lower and the enthalpy of the strand goes down.

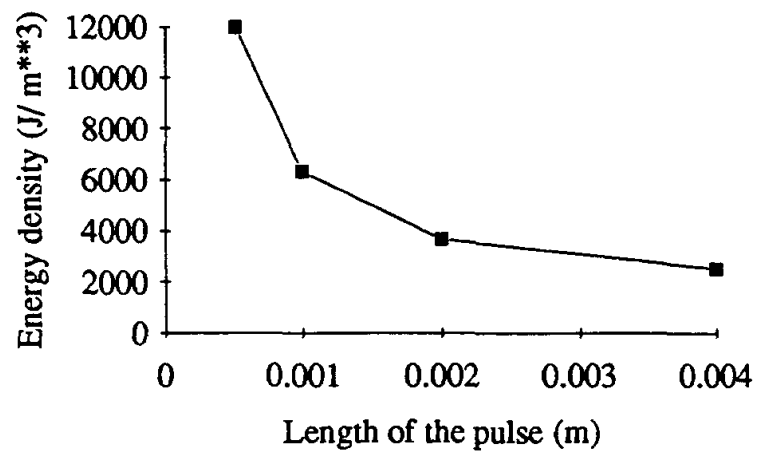

Fig. 3. Quench energy density as function of the length $\left(2^{*} \times 0\right)$ of the pulse at $T=1.9 \mathrm{~K}, \operatorname{tmax}=10 \mu \mathrm{s}, \mathrm{h}=0$.

\section{A. Influence of the Field}

The influence of the field is shown in Fig. 4 for a case with a short pulse and no heat transfer to the surroundings. Note that at $\mathrm{f}=\mathrm{It} / \mathrm{Iq}=0.7$ an optimum appears at $\mathrm{Cu}: \mathrm{Sc}=0.9$.

\section{B. Influence of the Pulse Duration and Heat Transfer to the Surroundings}

From Fig. 5 it can be concluded that it is favourable to use a low $\mathrm{Cu}: \mathrm{Sc}$ ratio at operating conditions.

\section{Comparison of $T=1.9$ and $T=4.3 K$}

A comparison between the heat needed to quench the strand at 4.3 and $1.9 \mathrm{~K}$ shows that about twice as much heat is needed at $4.3 \mathrm{~K}$ (Fig. 6). This calculation has been made for a strand operating at $90 \%$ of critical current on the load line.

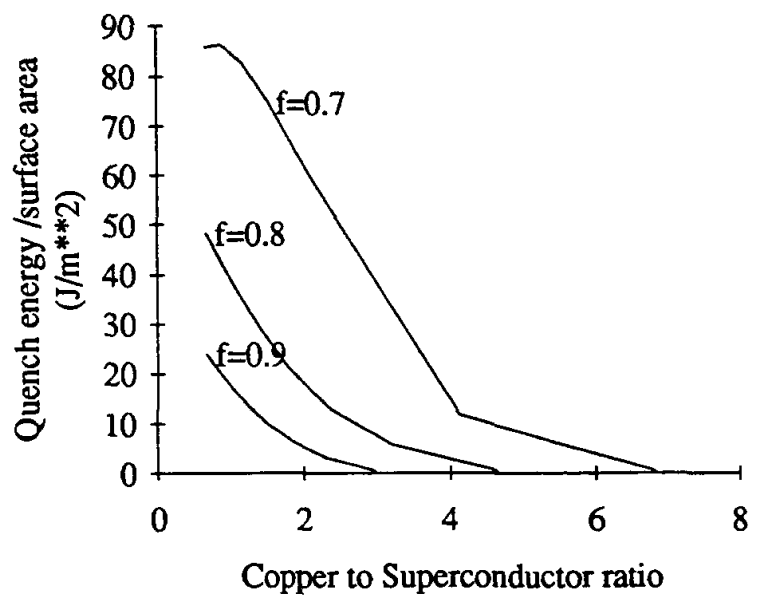

Fig. 4. Quench energy at various field levels at $1.9 \mathrm{~K}, \operatorname{tmax}=10 \mu \mathrm{s}, \mathrm{h}=0$. The 'f indicates the fraction of quench current or field. 


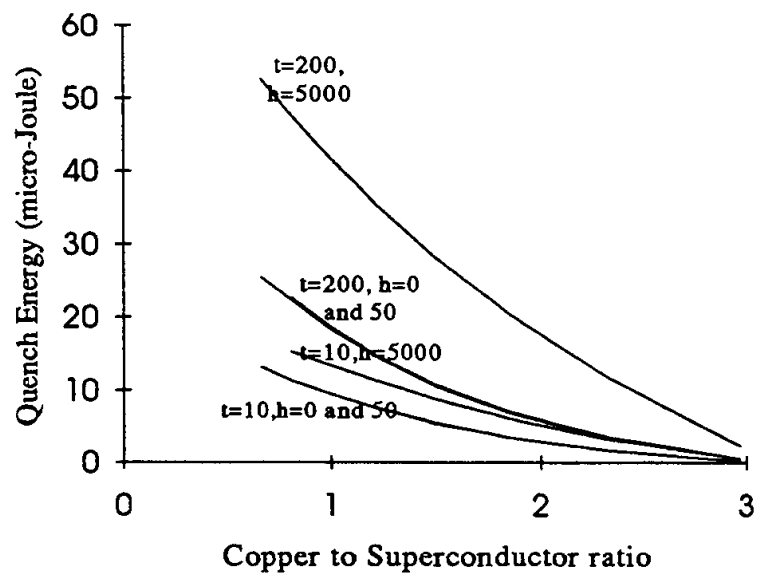

Fig. 5. Quench energy at $\mathrm{T}=1.9 \mathrm{~K}$ at $90 \%$ of quench current on the load line, for various duration ( $(\mathrm{t}$, in $\mu \mathrm{s}$ ) of the heat pulse and various heat transfer coefficients $\left(h^{\prime}\right.$, in $\left.W / m^{2} / K\right)$.

\section{CONClusions}

Both for thermal perturbations long in length ( $>2 \mathrm{~mm}$ ), of both short and long duration and for thermal perturbation short in length $(<2 \mathrm{~mm})$ within the assumed limits of pulse duration $(\leq 200 \mu s)$ and heat transfer $\left(\leq 5000 \mathrm{~W} / \mathrm{m}^{2} / \mathrm{K}\right)$, the optimum copper to superconductor ratio is rather low $(<1)$ at $\mathrm{T}=1.9 \mathrm{~K}$ in high fields. This conclusion that a low copper to superconductor ratio is favourable was also reached by several authors [3]-[6], [8] at 4.3K.

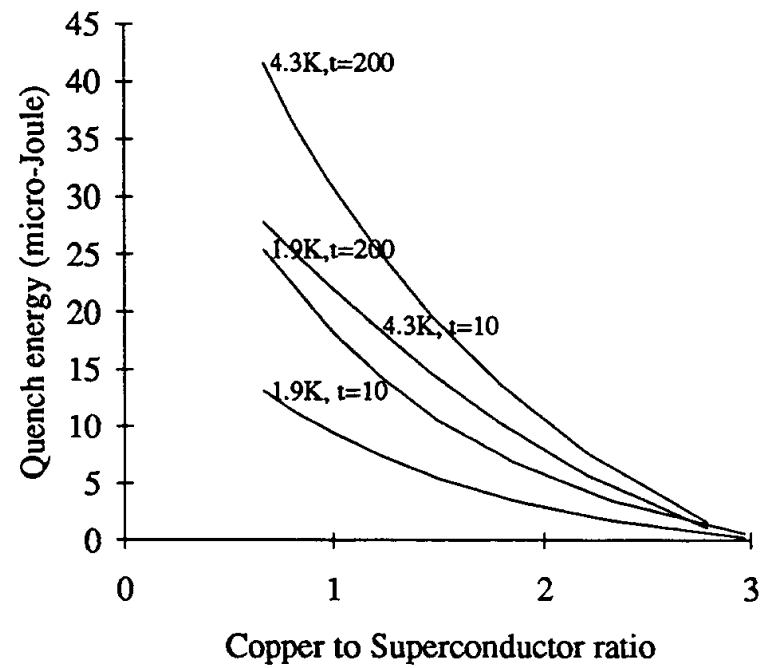

Fig. 6. A comparison of the heat needed to quench the strand at $1.9 \mathrm{~K}$ and $4.3 \mathrm{~K}$ operating at $90 \%$ of quench current on the load line. Pulse duration ( $\left.t^{\prime}\right)$ in $\mu s$. No heat exchange to the surroundings.

\section{ACKNOWLEDGMENT}

The author is very grateful to A. Siemko who made the analysis of the quench measurements.

\section{APPENDIX: MATERIAL PROPERTIES}

This appendix lists the material properties used for the calculations.

A. $N b T i$

$$
\begin{aligned}
& T C=9.2\left(1-\frac{B}{14.5}\right)^{0.59} J C=\left(J C 0-7.99 * 10^{8} B\right)\left(1-\frac{T}{T C}\right) \\
& C_{N b T i}=50 T^{3}+62 B T
\end{aligned}
$$

The thermal and electrical conductivity of $\mathrm{NbTi}$ are supposed negligible compared to those copper.

\section{B. Copper}

$$
C_{c u}=96.4 T+6.64 T^{3} \quad \rho_{C u}=\frac{1.70 * 10^{-8}}{r r r}+0.5 * 10^{-10} B
$$

For calculating the heat conductivity the WiedemannFranz law is supposed to apply: $\quad k_{C_{u}}=2.45^{*} 10^{-8} \frac{T}{\rho_{C u}}$

\section{REFERENCES}

[1] Leroy, R. Perin, G. de Rijk, W. Thomi, "Design of a high field twin aperture superconducting dipole model," IEEE Transactions on Magnetics, 1988, vol. 24, pp. 3466-3465.

[2] D. Leroy, J. Krzywinski, V Remondino, L. Walckiers, R.Wolf, "Quench observations in LHC superconducting one meter long dipole models by field perturbation measurement," IEEE Transactions on Applied Superconductivity, 1993, vol. 3, no.1, pp.781-784.

[3] X. Huang, S.W. Van Sciver, "The influence of $\mathrm{Cu} / \mathrm{NbT}$ ratio on the stability of high current density superconductor," Advances in Crygenics Engineering, 1992, vol. 37, Part A, pp. $299-306$.

[4] K.Y.Ng, "Minimum energy to start a quench and optimum copper-toNbTi ratio," Proc. of the 1989 IEEE Partical Acc. Conf., vol. 1, pp. 506-508.

[5] N. Amemiya and O. Tsukamoto, "Influence of copper to superconductor ratio on stability of superconductors," Cryogenies, 1991, vol. 31, pp. 528-532.

[6] W. V. Hassenzahl, "Study of the effects of copper to superconductor ratio on stability," Cryogenics, 1989, vol. 29, pp. 637-641.

[7] O. P.Anaskin, V.E.Keilin, V.VIyikov, "Influence of Cu/Sc ratio and filament distribution on the stability of superconductors with respect to local heat pulses," Cryogenics, 1981, vol. 21, pp. 169-174.

[8] KYoda, H. Yomoshimura, M Moritia, "Calculation of optimum Cu/Sc ratio to maximize superconductor stability," IEEE Transactions on Magnetics, 1991, vol. 27, no. 3, pp. 3466-3465.

[9] S. A. Elrod, J.W.Lue, J.R Miller, L. Dresdner, "Metastable superconducting composites: dependence of stability on copper-tosuperconductor ratio," IEEE Transactions on Magnetics, 1981, MAG17, no. 1, pp. 1083-1086.

[10] L. Dresner, "Quench energies of potted magnets," IEEE Transactions on Magnetics, 1985, MAG-21, no. 2, pp. 392-395.

[11] C. Meuris, "Heat transpont in insulation of cables cooled by superfluid helium," Cryogenics, 1991, vol. 31, pp. 624-628. 